\title{
Social Construction of Information Technology Supporting Work
}

Isabel Ramos, Universidade do Minho, Portugal

Daniel M. Berry, University of Waterloo, Canada

\section{EXECUTIVE SUMMARY}

In the beginning of 1999, the CIO of a Portuguese company in the automobile industry was debating with himself whether to abandon or to continue supporting the MIS his company had been using for years. This MIS had been supporting the company's production processes and the procurement of resources for these processes. However, in spite of the fact that the MIS system had been deployed under the CIO's tight control, the CIO felt strong opposition to the use of this MIS system, opposition that was preventing the MIS system from being used to its full potential. Moreover, the CIO was at lost as to how to ensure greater compliance to his control and fuller use of the MIS system. Therefore, the CIO decided that he needed someone external to the company to help him understand the fundamental reasons, technical, social, or cultural, for the opposition to the MIS system.

Keywords: $\quad$ business applications; case study; communications gap; enterprise IS; enterprise resource planning; IS impacts; IS problems; IS success; management information needs; organizational culture; social impacts; social issues of IT; top management; user attitudes; user behavior; user characteristics; user expectations; user satisfaction

\section{THEORETICAL BASIS FOR THE STUDY}

Innovative, organization-transforming software systems are introduced with the laudable goals of improving organizational efficiency and effectiveness, reducing costs, improving individual and group performance, and even enabling individuals to work to their potentials. However, it is very difficult to get these software systems to be used successfully and effectively (Lyytinen et al., 1998; Bergman et al., 2002). Some people in some organizations resist the changes. They resist using the systems, misuse them, or reject them. As a result, the goals are not achieved, intended changes are poorly implemented, and development budgets and schedules are not respected. Misguided decisions and evaluations and less than rational behaviour are often offered as the causes of these problems (Norman, 2002; Dhillon, 2004). Bergman, King, and Lyytinen (2002) observe (p. 168), “Indeed, policymakers will tend to see all problems as political, while 
engineers will tend to see the same problems as technical. Those on the policy side cannot see the technical implications of unresolved political issues, and those on the technical side are unaware that the political ecology is creating serious problems that will show up in the functional ecology." They go on to say (p. 169), "We believe that one source of opposition to explicit engagement of the political side of RE [Requirements Engineering] is the sense that politics is somehow in opposition to rationality. This is a misconception of the nature and role of politics. Political action embodies a vital form of rationality that is required to reach socially important decisions in conditions of incomplete information about the relationship between actions and outcomes."

The implementation of complex systems, such as enterprise resource planning (ERP) systems, are rarely preceded by considerations about:

- the system's degradation of the quality of the employees' work life, by reducing job security and by increasing stress and uncertainty in pursuing task and career interests (Parker and Wall, 1998, pp. 55-70; Davidson and Martinsons, 2002; Thatcher and Perrewé, 2002);

- the system's impact on the informal communication that is responsible for friendship, trust, feeling of belonging, and self-respect (Goguen, 1994; Snizek, 1995; Piccoli and Ives, 2003);

- $\quad$ the power imbalances the system will cause (Bergman et al., 2002; Dhillon, 2004); and

- the employees' loss of work and life meaning, which leads to depression and turnover (Parker and Wall, 1998, pp. 41-49; Bennett et al., 2003; Davison, 2002).

Recent work by Marina Krumbholz, Neil Maiden, et al. (2000) considers some of these issues after implementation of ERP systems. Specifically, this work investigates the impact on user acceptance of ERP-induced organizational transformation that results from a mismatch between the ERP system's actual and perceived functionalities and the users' requirements, including those motivated by their values and beliefs (Krumbholz et al., 2000; Krumbholz and Maiden, 2001).

This case study describes an on-site examination of one particular ERP-induced organization transformation. The prime champion of the ERP system in one company was surprised by the resistance to the system's use shown by the employees of the company. He ended up asking the help of the first author of this case study to understand the sources of this resistance and what to do about it. The present report is a distillation of the first author's final report to the champion and of her $\mathrm{PhD}$ dissertation (Ramos, 2000). The focus of the study is on understanding the technological, social, and cultural reasons of the employees' resistance against the ERP.

\section{ORGANIZATIONAL BACKGROUND}

The reader should consult the organizational charts shown in Figures 1 and 2 in Annex I as he or she is reading the following narrative. With the exception of the proper name Isabel, that of the first author, none of the proper names in the narrative, including 
of the company and of software products, is real. However, each proper name does refer to one real person, company, or product that participated in the events narrated.

One cold morning in February 1999, Pedro was talking with a friend, Sérgio, about Pedro's professional path as director of the Information Systems (IS) Department of ENGINECOMP, a Portuguese subsidiary of a Brazilian company in the automobile sector. Pedro was not able to decide what else could be done to ensure that MaPPAR, the information system that was currently supporting the management of production processes and the procurement of the associated resources, was used to its full potential.

Pedro had started working for ENGINECOMP at its very beginning in 1992, when the Brazilian company's administration decided to build a plant in Europe. They chose Portugal for its linguistic and cultural similarity, and for the relatively low salaries that would be paid to a young and educated workforce. See Annex II for details about the Portuguese automotive sector and about the company.

Rafael, the president of the Brazilian company, liked to have close control of the company and of all its branches. He felt especially comfortable with Pedro's past experience and thus hired Pedro. He also admired Pedro's creativity and close attention to details. Soon, Pedro earned the power to define the work processes, plant design, management practices, and the information systems that would support the work.

The building of the plant was finished in the beginning of 1993, and the plant was already manufacturing seven months later. It produced a small but essential component for the car engines. This component requires a high-quality production line, since even a small variance in the required measures implies that the product would not be accepted by the client.

The plant satisfactorily supplied several of the most important automobile builders in Europe. For each car model, the engineers of the plant, assisted by the client, designed the specific dimensions and shape of the product to be delivered each time it was ordered by the client. Simultaneously, the client and the plant administration negotiated the percentage of items that the client could cancel or add to an order already in production. This percentage was very important, since it helped the client to react quickly to a sudden drop or increase in the demand for that specific car model. For the plant, this variability added considerable difficulty to production planning, but the aggressive competitiveness of the automotive sector forced acceptance of these margins.

The raw material was shipped from Brazil, where the mines were located. The material was shipped by sea and arrived at ENGINECOMP three months later. This delay forced careful stock management and production planning.

Every time a new order arrived, ENGINECOMP's capability to produce the required product was carefully assessed. Following this assessment, the manufacture of the required product was planned to fit the delivery dates agreed upon with the client, and production orders were drafted and delivered to the plant. The production processes were designed in accordance with international norms and the best practices of the sector. These processes were regularly subjected to quality controls, in both external and internal audits.

Management of materials acquisition for the plant machinery was also an important task, since the plant could never stop or reduce its production from what was 
planned. Three employees of the Logistics Department were assigned to negotiate continually with actual or potential suppliers. These employees were responsible for keeping the materials at adequate stock levels.

Whenever ordered products were finished, they were packaged and were stacked in the warehouse for delivery. The finished goods were then delivered to their clients by ENGINECOMP's own trucks, by train, or by airplane.

Pedro decided that the complexity of all these activities required an integrated production management system. He convinced the Brazilian administration to buy a well-known and highly utilized off-the-shelf system, MaPPAR, to manage all the production processes and associated resources. See Annex III for details about MaPPAR. MaPPAR was configured and deployed under Pedro's tight control, with the assistance of the directors of several of ENGINECOMP's other departments, namely, Engineering, Quality Control, Finance, Logistics, and Warehousing.

Pedro told his friend, Sérgio, about all the difficulties and successes of the first two years. Pedro was really proud of his work and of his good decisions. ENGINECOMP was considered one of the best suppliers of its products in all of Europe and was supplying the most successful automobile manufacturers.

However, MaPPAR was never used to its full potential. In fact, resistance to MaPPAR's use seemed to grow steadily since its deployment. In parallel, Pedro's authority was being continually questioned despite his many past good decisions, his hard work, and his undeniable contributions to ENGINECOMP's success.

During 1998, a large fraction of ENGINECOMP's shares were sold to a German company. Now, the Brazilian company owned less than $40 \%$ of ENGINECOMP's shares and was thus losing control over what happened at ENGINECOMP. By the end of 1998, the only relics left of the Brazilian company's administration of ENGINECOMP were framed posters in the Brazilian Portuguese language encouraging employees' creativity and participation in decision making.

The new administrator, Fritz, distributed his control and support evenly over the directors of all departments that reported to him including the IS, Engineering, Quality Control, Finance, Logistics, and Warehousing departments. That is, Fritz treated Pedro for what Pedro really was, the director of the IS Department, one of many departments. Pedro resented this treatment, and he believed there was a close link between his loss of power and the growing opposition to the use of MaPPAR. He wanted to counter this opposition, but was having "difficulty reasoning unemotionally about the current situation and past events." Then, Sérgio told Pedro about a researcher who might be interested and able to help Pedro analyze the situation. The researcher was Isabel, who entered the scene in early March 1999.

\section{SETTING THE STAGE}

When Pedro first talked with Isabel, he told her about an important movement within ENGINECOMP against the use of MaPPAR to support production management. MaPPAR was very versatile and included modules that could support engineering tasks, order processing, production planning, assessment of production capabilities, pro- 
duction management, product shipment, management of stocks, accounts payable to suppliers, accounts receivable by clients, and finances and accounts management.

While MaPPAR was a very complete and powerful system, it was very poorly used. Employees ignored or resisted using much of MaPPAR's functionality, preferring to develop their own small systems and databases to manage only the information relevant to their daily tasks, and used the central MaPPAR database only as the source of data to feed their own small systems and databases.

Moreover, the employees of the plant were refusing to input timely data about the tasks they perform. They preferred to defer their inputting until the end of the week or the month, so they would not lose time during the days. Sometimes, one of the employees was freed by his colleagues from his normal duties in order to input his and his colleagues' data. The problem with this practice was that it became virtually impossible to track down the sources of the orders in production.

Pedro and Isabel agreed that Isabel would do an on-site study of ENGINECOMP at work, in search of the fundamental reasons, technical, social, or cultural, for the opposition to MaPPAR and for the proliferation of small systems and databases. Isabel would study the work of two departments in ENGINECOMP: the Finance Department and the Logistics Department. They were the most influential departments of the company, since they performed essential activities for the company. The Finance Department did financial management, and the Logistics Department did customer service and production planning. Moreover, the employees of these two departments constituted a majority of MaPPAR's users.

\section{CASE DESCRIPTION}

Isabel spent five months at ENGINECOMP, observing and interviewing all the employees of the Finance and Logistics departments. Almost every day, Isabel spent several hours joining or observing employees performing their tasks with or without support from MaPPAR. She interviewed Carlos and Manuel, the directors of the departments. She also interviewed several middle managers responsible for key activities, including Fernando, Carlos's closest collaborator in the Finance Department, and Roberto, Eduardo, and António, the managers of the Customer Service, Production Planning, and Purchasing divisions of the Logistics Department.

Isabel also observed and interviewed Pedro and his collaborators in the IS Department. She talked also a few times with the German leader, Fritz and she was present at events such as meetings and training programs. To learn more about MaPPAR, Isabel consulted the available manuals and technical documentation. She used a demonstration version of MaPPAR to test some of its functionality on her own.

Below is a department-by-department summary of Isabel's observations.

\section{Finance Department}

The Finance Department was responsible for all financial and accounting tasks of the company. Carlos, the director of the Finance Department, had sole directorial re- 
sponsibility for the department. However, he delegated supervision of the accounting tasks to Fernando, a trusted employee with an accounting degree. Fernando had access to key information and knowledge for performing these accounting tasks. Fernando's access and knowledge, charisma, and core skills made him a privileged ally of Carlos, the director.

As mentioned, the coordination and control of the Finance Department activities were responsibilities of Carlos, the director, who kept and centralized all decision making. Carlos was a Brazilian sent to ENGINECOMP by the Brazilian company's administration. Fritz, the new German leader, was not very comfortable with Carlos's complete control of the Finance Department.

In the Finance Department, informal communication about work tasks was discouraged. Carlos's rule was that all communication must be well documented. The work in the department was organized into well-defined tasks connected by clearly defined processes, all of which determined the precise responsibilities of each employee. Employees only occasionally received professional training. The heavy workload left little time for such training. Moreover, Carlos believed that each employee must perform simple and repetitive tasks that can be learned by doing. The tasks were distributed among eight employees, each with limited autonomy. Carlos had his trusted assistant Fernando, with the accounting degree, supervise the daily routine.

Fernando was seen as a bright and ambitious young man. He was expected more to comply with rules and procedures than to make autonomous decisions. Fernando worked hard to serve Carlos's interests, taking advantage of what he had learned in courses leading to his degree to further those interests. Fernando's actions and information were especially useful to Carlos, who as a Brazilian, was not as familiar with Portuguese accounting regulations as a Finance Department director should be.

It is I who signs the accounts, the financial reports, and the balance sheets. It is I who signs the fiscal statements. I am the officer responsible for the company's accounting. My accounting degree and my understanding of Portuguese law allow me to give invaluable assistance to the director. - Fernando

With the help of Fernando, Carlos asserted the strong leadership that Carlos believed was the guarantor of efficiency and motivation. Compliance with Carlos's leadership was the main criterion by which Carlos recruited employees the Finance Department.

Interviewed Finance Department employees mentioned some competition for career advancement. Finance Department employees were rewarded for accurate completion of assigned tasks. Failure to comply with rules and procedures was punished. There was a predominant belief among the employees that autonomous and creative employees were dangerous in a finance department. This belief was supported by past events during which fraud was perpetrated. This belief was one of the most important sources of the motivation to use MaPPAR, which was seen as reinforcing established practices:

I am responsible for one area. So, I work in a well-defined set of tasks and my colleagues have clearly defined tasks as well. There is no confusion. The system requires that we are specialists 
in our tasks ... hmm ..., and it assures that our director has access to what we do, so we are not blamed for the mistakes [errors and fraud] of others. - An Employee of the Finance Department

There was little variation in the daily routine of the Finance Department. All needed information was in MaPPAR's database, and that information was provided by the other departments of ENGINECOMP. Moreover, a significant part of the Finance Department's work was the production of regular reports and other more timely, but irregular information for the other departments. The other departments of ENGINECOMP exerted the most influence on the Finance Department and served as a buffer between the Finance Department and the company's clients and suppliers. However, the Finance Department did have some interaction with banks and other similar entities outside the company. Thus, as can be expected, the Finance Department's workload was very stable, with almost no surprises.

The Finance Department employees made heavy use of spreadsheets to produce the reports the department was required to produce for the other departments. The reasons offered for use of spreadsheets instead of MaPPAR included:

The [MaPPAR] system reports are not adequate for our management needs. They present too much data, in a lot of rows, many of which are not useful. It is better to search for the relevant data using query tools and then to export the data to our spreadsheets where we can treat the data in the way that suits our objectives. - Fernando

Despite that the use of spreadsheets was sanctioned for the production of only specific reports, the spreadsheets were being programmed to also perform some functions that the system provided.

There is no need to use the options provided in the menus of the [MaPPAR] system because we have other tools that do the same. - Another Employee of the Finance Department

Some Finance Department employees regretted the lack of training to use MaPPAR. At the time MaPPAR was installed, MaPPAR's implementers did train the Finance Department employees that were hired specifically to operate MaPPAR. However, these employees saw the training as too brief and too compressed; they simply could not absorb all the complex information about MaPPAR's functionality in such a short time. Hence, from the beginning, even the MaPPAR operating employees did not understand MaPPAR's full capabilities.

It was a one-shot training. I would not even call it training; it was more like a conversation with the technicians. - Still Another Employee of the Finance Department

After that initial training, employees that had used MaPPAR for a longer time were responsible for in-house MaPPAR training. Often these trainer employees guided the trainee employees through only the functionality actually being used. The trainers usually advised trainees to avoid other MaPPAR functionality, saying that it would be too complex, inadequate, or better implemented in the programmed spreadsheet. 
All that I know about the system is the result of my efforts to use it. But we have too many tasks to perform. There is no time left to explore the system, which has too many complexities. And I say to my colleagues that they should not waste too much time experimenting if they are not sure of the usefulness of a menu's options. - Fernando

The Finance Department employees saw this in-house training as a burden. Moreover, Carlos did not encourage his employees to experiment with MaPPAR themselves.

The Finance Department's history included some catastrophic mistakes, and the department rumor mill still propagated stories about the stupid mistake that Employee A or Employee B had made.

To many Finance Department employees, the spreadsheet appeared much easier and less constraining than did MaPPAR.

All requests for required new or enhanced features for MaPPAR were sent to the IS Department for implementation. However, many times the IS Department's response was to deny a request because of the high costs of the new or enhanced feature. The IS Department did not want to have to make the same changes to every new version of MaPPAR that would come out in the future. When a required feature was refused by Pedro, the director of the IS Department, the requesters were able to easily find implementers among their colleagues, who had accepted the informal responsibility of programming the spreadsheets and databases.

In general, Finance Department employees acknowledged the importance of MaPPAR for their department, since MaPPAR's integrated modules automatically fed all the accounts. The institutional authority of the IS Department to define MaPPAR's IT support was well accepted.

\section{Logistics Department}

The work of the Logistics Department was distributed among three divisions: Purchasing, Customer Service, and Production Planning. António, the manager of the Purchasing Division, Roberto, the manager of the Customer Service Division, and Eduardo, the manager of the Production Planning Division, each reported directly to Manuel, the director of the Logistics Department. Each of the three managers coordinated and controlled the tasks for which he was responsible. The three managers and one director participated jointly in defining the Logistics Department's goals and objectives and in decision making.

Professional training was being delivered to Logistics Department employees on a regular basis. However, each of the three managers believed that his skills were not being adequately used and rewarded. In particular, the Customer Service Division manager, Roberto, felt especially frustrated with this situation. Roberto was seen as a very dynamic man who learned his job quickly and tried to exceed what was expected from him. However, Roberto felt that MaPPAR was a significant barrier to his own career advancement. MaPPAR demanded too much specialization in specific tasks and made it difficult for one person to have a broad perspective of the business processes. Roberto believed that this broad perspective was central to providing effective customer service and to making good decisions. 
Here [at ENGINECOMP], we are evaluated by our ability to solve problems. To be able to solve problems quickly, we need to know what is going on around here. But, the system is so unnecessarily complex, and it limits our ability to access relevant information. - Roberto

In fact, it was Roberto who took the initiative of programming the spreadsheets and databases that were being used by his colleagues throughout ENGINECOMP. He and two other employees in the Customer Service Division became the informal IS team of ENGINECOMP, always ready to implement new features adapted to the specific needs of their colleagues. Roberto's informal, can-do attitude, his enthusiasm in searching for solutions, and his courage to directly face senior managers provided him with the admiration of his colleagues, inside and outside the Logistics Department. Roberto proudly said,

"At this stage of my career, I am independent of the director of the department. I report directly to the administration [i.e., Fritz]."

There was a widespread belief among all ENGINECOMP's employees that the Logistics Department created the company's positive image among its customers and the general public. This belief was a source of negotiating power for the Logistics Department and especially for its emerging leader, Roberto.

Especially during the last three months, we ... When I joined the department, we contacted one client directly, and the others were contacted through our office in Hamburg. In fact, it was not a real department but an expedition unit. With the recent closing of the office in Hamburg, all the logistics service is provided by Portugal. Of course, this gave us much more importance inside the company. - Roberto

Roberto was the manager of one of the three divisions of the Logistics Department officially directed by Manuel. Manuel and the managers of the three divisions believed that the four of them should cooperate to achieve the department's goals. However, frequent internal conflicts emerged from the fights over the specific interests of the department's divisions. These conflicts emerged from the need to fight for scarce resources such as budget, human resources, and technology. The conflicts also arose from the conflicting influences on work practices exerted by António, the Purchasing Division manager, and Roberto.

We're working differently now. We have three autonomous divisions. We [managers of the divisions] are responsible for ensuring that our colleagues have what they need to perform their tasks. Hmmm ... Who coordinates our activities? Well, that is a difficult question. The department's director, I guess ... [laughter]. Well, I talk directly with the administration [Fritz]. - Roberto

The Logistics Department office space was designed as an open space into which any ENGINECOMP employee could enter to seek a problem solution or to demand a service. The Purchasing Division and the Production Planning Division managers often 
complained about deleterious effects and the pressure caused by the constant interruptions that the open space invited:

There is always pressure from the exterior of the department. This is a drawback of the clientsupplier policy that was adopted internally, this pressure to be continuously available in open space. We are constantly being interrupted! It is not possible to focus our attention on a single subject for long and to follow logical and correct reasoning. - António

Adding to this pressure were the variable and often unexpected requests and problems posed by suppliers, clients, and ENGINECOMP's production plant. For example, as mentioned, the quantities ordered by a costumer could be changed within an agreed upon percentage after the order was placed and production had started. Logistics Department employees saw flexibility of work practices and procedures, autonomy of decision, and informal communication channels and work relations as key factors to reduce the negative impacts of these sudden changes. Moreover, they saw MaPPAR as reducing their flexibility of action and making their work less interesting. Furthermore, MaPPAR was forcing them to comply with rules and procedures that reduced their ability to fulfill the needs of ENGINECOMP's plant and customers.

Some of these Logistics Department employees referred to MaPPAR as a "sacred cow" that could not be questioned and that made them "slaves," requiring most of their time to input data without "receiving anything in return." These employees complained also of the poor quality of the MaPPAR reports. They had become highly suspicious of the data stored in the central database.

Because people won't be wasting their time to explore this and that. Why should they? When I want a report and this [MaPPAR] does not give me what I want ...! If only they [IS Department] made changes to the system! Meanwhile, someone [from the IS Department] decides not to make them. It is frustrating. - Eduardo

As in the Finance Department, the reports needed to support Logistics Department decisions were created in spreadsheets, using data obtained by querying the central MaPPAR database. This practice fostered a disconnection between the inputting of data and the production of reports to support decision making. The Logistics Department employees saw MaPPAR as too complex and too general to effectively support the details of the department's activities. Logistics Department employees agreed with Finance Department employees about the lack of MaPPAR use training and the burden caused by having to train new employees in the use of MaPPAR.

Ifind the system too confusing. It is a tool, since it is a standard in a lot of business areas. I think it does not really help the specific tasks of a specific company in a small country like ours. António

Also, the Logistics Department employees decried the IS Department's lack of support and understanding. In response to this complaint, the Logistics Department developed what Roberto believed was a very effective strategy: 
I have been doing [developing any needed functionality] by myself. When they [the IS department] do not want to make the [required] changes to the system, I develop the feature using the spreadsheets and databases. Nowadays, I do not even ask; I do by myself and help others with the programming. - Roberto

And he added:

The lack of support from the IS department is creating disinterest in the system. - Roberto

The removal of MaPPAR was seen as an important step to gain more control over the performed work. Employees wanted to be involved in (i) defining the work practices, (ii) decision making, (iii) monitoring the system usage, and (iv) defining what were good and bad usages.

This plant is six years old now. We have learned a lot. We want to be heard! We need a new system, but this time, we want to be involved! - Roberto

\section{The IS Department}

As mentioned, Pedro was the director of the IS department. He kept close at hand the responsibility to define the operational and management best practices and to ensure that the information systems were effectively supporting those practices.

Also mentioned, Pedro was very proud of his professional advancement and his contributions to the success of ENGINECOMP. He considered himself responsible for the formulation of creative solutions in both work practices and information systems. He considered that implementing these solutions was a task to be performed in collaboration with the affected departments. Pedro did not consider himself to be an IS technical expert. His closest collaborator was the person that knew the used systems in detail and would do all the programming, parameterization, and users' support. This collaborator, José, was a timid man with strong technical skills; he was very competent, but was hardly considered a leader of opinion and action.

He [José] is very competent. I trust all technical tasks to him - Pedro

José works hard. He always treats us right. The only thing is ... Well, he is very silent [smiling]. - Roberto

José was well accepted by employees from the other departments. These other employees understood the difficulty José had in providing immediate support to all MaPPAR users. José's colleagues from the other departments found José easier to approach than Pedro and they preferred to talk with José first when a problem arose or when a change to MaPPAR was needed. However, these employees knew also that José's actions were constrained by IS Department policies and his manager Pedro. At one point, the managers of departments other than the IS Department were informally discussing the role of the IS Department. A clear line was emerging between those that 
supported Pedro's interventional attitude and those that supported José's helpful and cooperative attitude. Pedro was aware of this discussion but showed no resentment towards José.

I know that they [the other employees] would like to get rid of me [laughter]. I defend the company interests too much. Of course, some other people around here understand that I have dedicated my life to this company. This happens everywhere and is tough. I do not believe José could handle all this. - Pedro

Pedro saw José as a very good programmer that would never be able to carry out the negotiation and political battles inherent in Pedro's, the IS director's, job. Moreover, Pedro knew that José was oblivious to the discussion. Pedro understood this discussion as an expression of the growing resistance to his own actions. What Pedro really resented was that the German administration and Fritz, in particular, were listening to these dissenting voices more and more.

The Brazilian administration understood. They hired me for my competence, and they saw what I did. The new administrator does not know. - Pedro

\section{CHALLENGES FACING THE ORGANIZATION}

By the end of the Isabel's study, the company was undergoing important changes in its middle management structure. Carlos resigned when a new directorial opportunity was offered to him back home in Brazil.

Roberto was becoming a key player in the growing importance of the Logistics Department within ENGINECOMP and in the good image this department projected to the company's stakeholders. Manuel, the Logistics Department director, was losing control over departmental decisions and strategy definition.

The German parent company was using a different ERP system, SAP R/3, and was now weighing the cost-benefits tradeoffs between upgrading ENGINECOMP's MaPPAR to interface with the parent company's system and deploying SAP R/3 at ENGINECOMP. Roberto believed that SAP R/3 should be deployed at ENGINECOMP. Roberto believed also that ENGINECOMP's six-year use of some ERP system, albeit different from SAP R/3, gave ENGINECOMP's middle managers the technological knowledge to actively participate in the parameterization of SAP R/3. The Finance Department did not have any preference, and its director was concerned only with the costs of the new system. Pedro was against the deployment of SAP/R3 because of the high costs of process reengineering and user training.

Some were suspicious of the data stored in the central database. The reluctance to use MaPPAR and the lack of time and will to explore MaPPAR's full functionality resulted in data being entered late or not at all, with the usual deleterious effects. For example, it was not always possible to track a client's order when the client requested information about his or her order. There were also problems identifying what products and raw material were in stock. 
The growing trend to use spreadsheet programming to get around the problems caused by MaPPAR or to implement functionality perceived as not available in MaPPAR was also reducing the data's quality. Often, results of outside data processing were not fed back into MaPPAR.

Important MaPPAR functions, such as requirements planning and capacity planning, were never utilized and were instead programmed outside MaPPAR, resulting in unnecessary maintenance costs, lack of control over planning and its results, and a severe risk of unreliable planning. Pedro's efforts to document (1) organizational processes and resources, (2) the decision to deploy MaPPAR, (3) the MaPPAR process, (4) MaPPAR's functionalities and upgrades, and (5) the IT structure of ENGINECOMP supported his conviction that there was no need to incur the high costs of switching to a different system, especially when the European economy, including its automotive sector, was slowing down. Pedro realized that prevailing with this view would require gaining allies within ENGINECOMP and gaining the explicit support of Fritz, a near impossibility. Pedro just did not know what else could be done to get people to see the importance of abandoning the small databases and in-house programming in favour of a fuller understanding and use of MaPPAR.

\section{REFERENCES}

Bergman, M.B., King, J.L., \& Lyytinen, K. (2002). Large-scale requirements analysis revisited: The need for understanding the political ecology of requirements engineering. Requirements Engineering Journal, 7(3), 152-171.

Bennett, J., Stepina, L. P., \& Boyle, R. J. (2003). Turnover of Information Technology workers: Examining empirically the influence of attitudes, job characteristics and external markets. Journal of Management Information Systems, 19(3), 231250.

Bergman, M.B., King, J.L., \& Lyytinen, K. (2002). Large-scale requirements analysis revisited: The need for understanding the political ecology of requirements engineering. Requirements Engineering Journal, 7(3), 152-171.

Davison, R. (2002). Cultural complications of ERP: Valuable lessons learned from implementation experiences in parts of the world with different cultural heritages. Communications of the ACM, 45(7), 107-111.

Davison, R. \& Martinsons, M.G. (2002). Empowerment or enslavement? A case of process-based organisational change in Hong Kong. Information Technology \& People, 15(1), 42-59.

Dhillon, G. (2004). Dimensions of power and IS implementation. Information \& Management, 41(5), 635-644.

Goguen, J.A. (1994). Requirements engineering as the reconciliation of technical and social issues. In J. A. Goguen \& M. Jirotka (Eds.), Requirements Engineering: Social and Technical Issues (pp. 165-199). London: Academic Press.

Krumbholz, M., Galliers, J., Coulianos, N., \& Maiden, N.A.M. (2000). Implementing enterprise resource planning packages in different corporate and national cultures. Journal of Information Technology, 15, 267-279. 
Krumbholz, M., \& Maiden, N.A.M. (n.d.). The implementing of ERP packages in different organisational and national cultures. Information Systems Journal, 26(3), 185-204.

Lyytinen, K., Mathiassen, L., \& Ropponen, J. (1998). Attention shaping and software risk: A categorical analysis of four classical risk management approaches. Information Systems Research, 9(3), 233-255

Norman, D.A. (2002). Emotion and design: Attractive things work better. Interactions, 9(4), 36-42.

Parker, S. \& Wall, T. (1998). Job and Work Design: Organizing Work to Promote Well-Being and Effectiveness. Thousand Oaks, CA: Sage Publications.

Piccoli, G. \& Ives, B. (2003). Trust and the unintended effects of behavior control in virtual teams. MIS Quarterly, 27(3), 365-395.

Ramos, I.M.P. (2000). Aplicações das Tecnologias de Informação que suportam as dimensões estrutural, social, política e simbólica do trabalho. PhD Dissertation. Departamento de Informática, Universidade do Minho, Guimarães, Portugal.

Snizek, W.E. (1995). Virtual offices: Some neglected considerations. Communications of the ACM, 38, 15-17

Thatcher, J. B. \& Perrewé, P. L. (2002). An empirical examination of individual traits as antecedents to computer anxiety and computer self-efficacy. MIS Quarterly, 26(4), 381-396.

Isabel Ramos earned her PhD in Information Technologies and Systems from the University of Minho (2001). She is currently an assistant professor in the Information Systems Department, University of Minho, Portugal. She leads a research group in knowledge management. She also conducts research in requirements engineering. She is an associate editor of the new International Journal of Technology and Human Interaction. Other research and teaching interests include organizational theory, sociology of knowledge, history of science, and research methodology. She has authored several scientific papers presented at international conferences and workshops, and published in conference and workshop proceedings and journals.

Daniel M. Berry earned his PhD in Computer Science from Brown University (1974). He was on the Faculty of the Computer Science Department at the University of California, Los Angeles (1972-1987). He was with the Computer Science Faculty at the Technion, Israel (1987-1999). From 1990 to 1994, he worked for half of each year at the Software Engineering Institute at Carnegie Mellon University (USA), where he was part of a group that built CMU's Master of Software Engineering program. During the 1998-1999 academic year, he visited the Computer Systems Group at the University of Waterloo in Waterloo, Ontario, Canada. In 1999, Dr. Berry moved to the School of Computer Science at the University of Waterloo. His current research interests are software engineering in general, and requirements engineering and electronic publishing. He has supervised 21 PhDs, numerous master's students, and has received a Noted Instructor Award in Computer Science at Technion. He has consulted extensively in industry. He has served as associate editor for two journals and has been a referee for numerous journals. He has chaired and participated on programming committees for many conferences and workshops. He has published extensively in refereed journals and contributed to many refereed conferences, symposia, and books. 


\section{APPENDIX I}

Figure 1: Organizational Chart until 1999

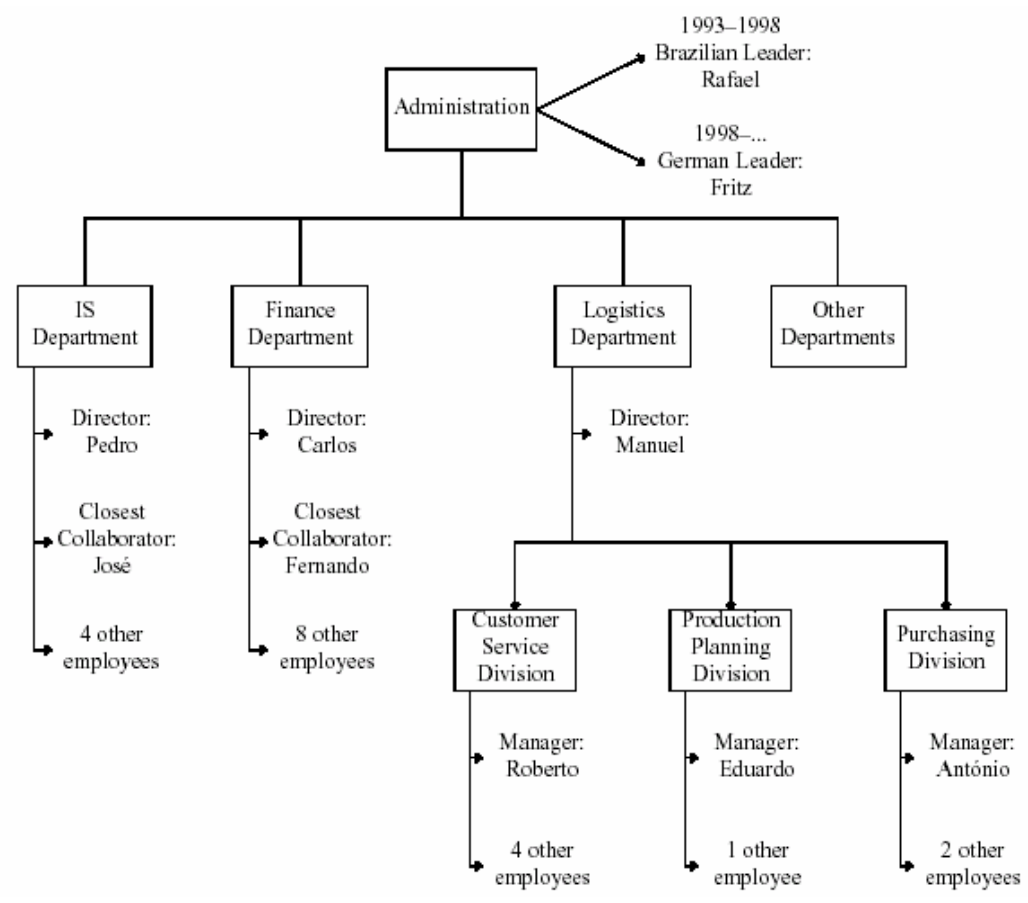

Figure 2: Organizational Chart after 1999

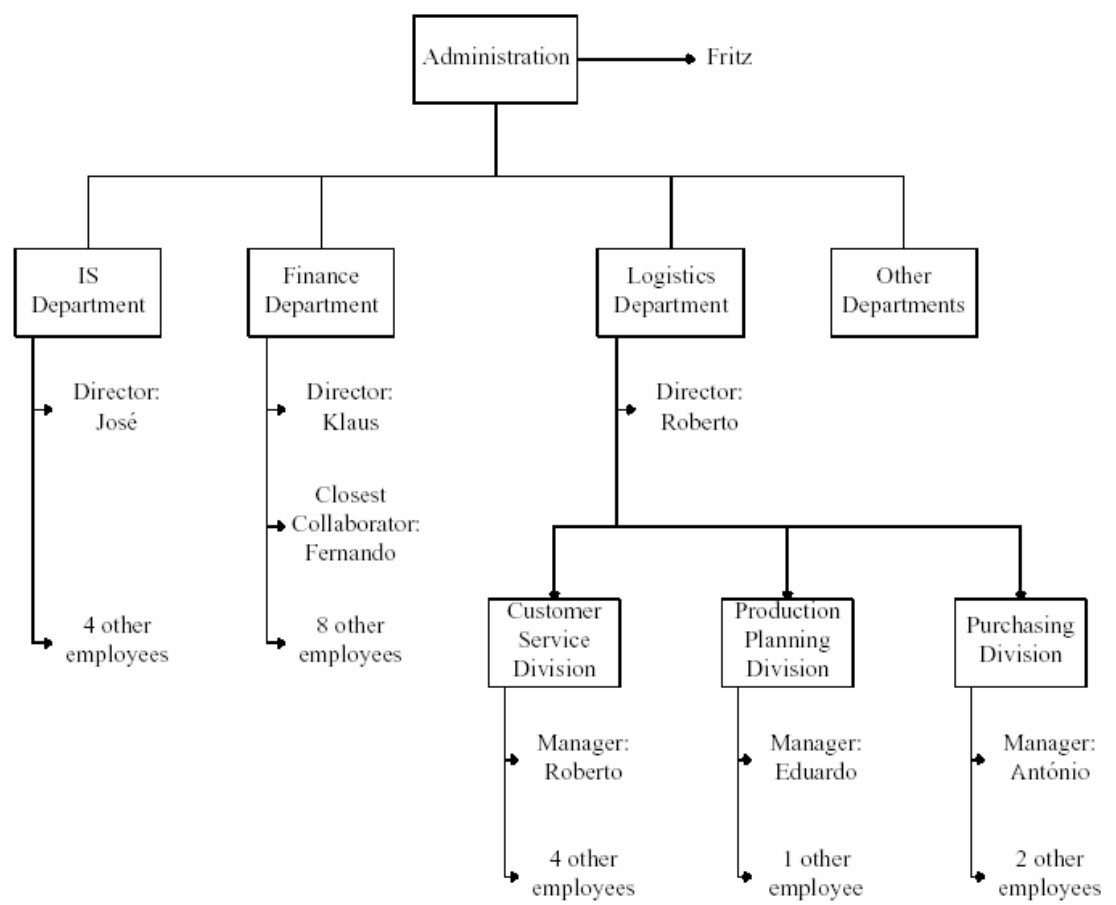

Copyright $\odot$ 2005, Idea Group Inc. Copying or distributing in print or electronic forms without written permission of Idea Group Inc. is prohibited. 


\section{APPENDIX II}

\section{The Automotive Sector in Portugal}

The automotive industry in Portugal generates, per year, more than 6.6 billion Euros, of which 4.1 billion are in automobile components. It currently employs more than 45,000 workers. Investment in the automotive component industry continues to attract a large number of investors and is strongly supported by both Portuguese Government and European Union funds.

The main areas of automotive production in Portugal include electronics, die castings, plastic parts, seats, and climate control systems. Manufacturers, including Volkswagen, Mitsubishi, Opel, Toyota, and Citroen, assemble more than 240,000 cars per year in Portugal. Portugal and Spain together make up the third largest car producing region in Europe. More than $80 \%$ of the vehicles produced in Portugal are exported to other European countries.

Portugal's automotive component industry, comprising 160 companies, focuses on engines, engine components, moulds, tools, and other small parts.

\begin{tabular}{|l|r|}
\hline Number of Companies & 160 \\
\hline Directly employed staff & 37500 \\
\hline Turnover (billion Euro) & 4112 \\
\hline Exports (billion Euro) & 2642 \\
\hline
\end{tabular}

Source: AFIA (2002) (http://www.afia-afia.pt/)

\section{Components Industry Evolution}

\begin{tabular}{|c|c|c|c|}
\hline Years & National Market & Exports & Turnover \\
\hline $\mathbf{1 9 8 6}$ & 200 & 224 & 424 \\
\hline $\mathbf{1 9 9 0}$ & 329 & 798 & 1.127 \\
\hline $\mathbf{1 9 9 4}$ & 434 & 1.786 & 2.220 \\
\hline $\mathbf{1 9 9 8}$ & 1.352 & 2.319 & 3.671 \\
\hline $\mathbf{2 0 0 3}$ & 1.460 & 2.834 & 4.294 \\
\hline
\end{tabular}

Source: AFIA (2002) (http://www.afia-afia.pt/)

\section{ENGINECOMP: Organizational Units, Business Vision \& Mission, International Norms Adopted}

The company's headquarters are in Brazil. The company has plants in Brazil, Portugal, and Argentina. It has commercial offices in Germany, the United States, Uruguay, and Ireland. 


\section{ENGINECOMP}

Vision

To be acknowledged worldwide as a competitive, high technology manufacturer that respects the environment.

\section{Mission}

To be the principal producer of the XYZ car engine component for the European market, aiming at complete client satisfaction; to achieve a high return on its invested capital.

International Norms Adopted: QS 9000/ ISO 9001, VDA 6.1, BS 7750

\begin{tabular}{|l|l|}
\hline Number of Employees & 800 \\
\hline Turnover (Million Euro per year) & 30 \\
\hline Exports (Million Euro per year) & 20 \\
\hline
\end{tabular}

